\section{MEDAL AWARDS FOR 1943 OF THE ROYAL SOCIETY*}

\author{
Copley Medal
}

$\mathrm{T}$ HE Copley Medal is awarded to Sir Joseph Barcroft, emeritus professor of physiology in the University of Cambridge, and now the head of a research unit established there in animal physiology.

The researches on the respiratory function of the blood, in respect of which this highest of the distinctions in the Society's gift is awarded this year, have occupied a central position in Barcroft's life-work. Their record is one of steady purpose and unbroken progress over a period of some forty-five years. At Barcroft's own hands, and at those of the long and very distinguished succession of collaborators who have been associated with him, these researches have had many important extensions into neighbouring fields of biological inquiry; they have played a great part in a wide range of recent advances in physiological, biochemical and medical science throughout the world; and they have been an important factor in the creation of a scientific basis for the study of manifold human activities, of work and of play, in peace and in war.

As a newly graduated student at Cambridge, Barcroft seems to have seen already the significance of the problem to which he was thus to devote so many years of fruitful investigation, recognizing the respiratory function of the blood as a condition of the life and a measure of the metabolic activity of every part of the body of the higher animals. With a cumbrous equipment of pumps and their accessories, alone available for such determinations in those early days, he applied himself with great determination and ingenuity to a study of the changes of oxidative metabolism which accompany secretory activity in the salivary gland. From that beginning his researches grew and developed in logical sequence, including studies of oxidative metabolism in relation to specific activity in the kidneys, the liver, the muscles and other organs, with various excursions to deal with corollaries from this central theme.

Early in the series came Barcroft's invention of a comparative manometric method, which effected a revolutionary simplification of the technical operations involved in obtaining the data required. The same method enabled him, in due course, to make his classical redeterminations of the relation between the pressure of oxygen and its combination with, or release from, blood or solutions of hæmoglobin, and of the effects of varying conditions on the graphs representing that relation. The principle of this method, as employed either in Barcroft's own original apparatus, or in the more delicate micrometric form which Warburg later introduced, has passed into standard use in every laboratory of functional biology throughout the world, for measuring rates of respiratory metabolism in surviving samples of living tissues and of various chemical changes due to artificial enzyme systems. Barcroft and his companions in research have used it, in expeditions which he led to Monte Rosa and to the Andes, to study the modifications of man's physiology by life at high altitudes and at low oxygen tensions, providing knowledge which to-day has an ever more urgent application to the problems of human flight; and in

* Remarks made by Sir Henry Dale in presenting the awards on November 30 . two successive wars Barcroft himself has used the knowledge built up and the skill acquired in his peaceful researches to the direct aid of his country in its need.

Studies of the differences between the respiratory functions of the blood in fotal and independent life led. Barcroft, with a characteristic readiness to follow the lead of natural interest, into a neighbouring field of inquiry, to a more general study of the physiology of mammalian foetus, and thus to the results which he reviewed in the Croonian Lecture of 1935 on "Fœtal Respiration". His need, for that purpose, to make observations on larger animal types, such as the sheep, led again to a wider interest in the physiology of farm animals, and so to the new enterprise for which his more recent research appointment provides welcome opportunity.

In a preface to his book, Joseph Barcroft finds a connexion between what he learned in sailing boats and what he has done in research. We may think of him, perhaps, as one whose instinct and aptitude have led him to venture as an explorer beyond visible horizons, rather than to sound remoter depths of theory in seas already known. Such a thought would place him in a long tradition of this Society, in company with such great students of the respiratory function as Boyle, Hooke, Mayow and Lower among our earliest fellows, and, of those who over the centuries have received this Copley Medal, with Stephen Hales and Joseph Priestley and, most intimately of all, with John Scott Haldane, who received it nine years ago. Barcroft's work, like Haldane's, of high scientific merit in itself, has extended its influence far beyond the laboratory over a wide range of the beneficent and creative activities of mankind at peace, and now again, for the last time let us hope, to those imposed by the dire compulsion of war. We rejoice to know that in him the hunger for knowledge is still unsatisfied, and that he is still sailing his craft towards new horizons.

\section{Royal Medals}

A Royal Medal is awarded to Sir Harold Spencer Jones, Astronomer Royal for England, in recognition of his determination of the solar parallax and of other fundamental astronomical constants.

Much of the earlier work of Spencer Jones was devoted to the discussion of certain fundamental astronomical constants, and in this field of work he was long ago recognized as a leading authority. At the meeting of the International Astronomical Union held at Leyden in 1928, a Solar Parallax Commission was appointed, with Spencer Jones as president, in preparation for the favourable opposition of the minor planet Eros in 1931.

The planning and co-ordination of the enterprise of redetermining the solar parallax, in which twentyfour observatories took part, fell mainly upon him, and he was entirely responsible for the assemblage of the material, and for the derivation of the results. It is to be noted also that the Cape Observatory, of which he was then director, made the greatest contribution to the observational material. The circumstances of the opposition favoured southern observatories, and the plates obtained at the Cape contributed more weight than those from all the other observatories combined.

The whole task of reduction of the observations was carried out under Spencer Jones's supervision, and the memoir which contains the complete discussion of the material and the results obtained from 
it (Mem. Roy. Astro. Soc., vol. 66, part 2; 1941) is a masterly exposition of the whole subject of the investigation of solar parallax and of the interrelated constants.

The solar parallax finally derived is given as $8 \cdot 790 \pm 0.001$, as compared with the value of $8 \cdot 806 \pm 0 \cdot 004$ obtained by A. R. Hinks at the preceding opposition of Eros in 1900-1. Spencer Jones found complete agreement between the results derived separately from northern and southern observatories, or from right ascensions and declinations separately, or from photographic and photovisual telescopes, or from primary and secondary stars, as well as from four successive periods of time during the opposition. No matter how the material was subdivided, no substantial difference could be found in the value of the solar parallax derived. There is thus every reason to think that systematic error has been eliminated, and that the probable error of 0.001 truly represents the high degree of accuracy of the final result. Therewith we are given a new estimate of the earth's distance from the sun, which is likely to stand without revision for many years. These observations on Eros also yielded a new estimate of the mass of the moon, which has less than half the probable error of the previous determination.

The modification of the previously accepted value of the solar parallax affects the estimates of other astronomical and geophysical constants. Spencer Jones's work is enhanced by his discussion and general adjustment of the values of all these interrelated constants, and in this he makes a substantial new contribution to the problem to which so much of his earlier work was devoted.

A Royal Medal is awarded to Dr. E. B. Bailey, director of the Geological Survey of Great Britain, in recognition of his contributions to the knowledge of mountain structure and his studies on the tectonics of vulcanism.

The number, range, and importance of Bailey's contributions to geology can have few parallels in the history of this science in Britain. It is only necessary to review his major publications to recognize the solid achievements that stand to his credit in the diverse fields of petrography, tectonics, stratigraphy, glaciology and physiography. But it is more particularly by his outstanding contributions to the knowledge of mountain structure and on the tectonics of vulcanism that he is to-day acknowledged internationally as a leader.

His work on mountain structure is contained in a long series of memoirs on the non-fossiliferous schists of the Southern Highlands of Scotland. These studies, prosecuted far across country and presented in a brilliant synthesis of the structure over a large part of the south-west and central Grampians, mark a great advance in the field of mountain tectonics and have provided a notable stimulus to research on Highland geology.

Bailey's now classic researches undertaken in conjunction with Clough and Maufe on the Devonian volcanic cauldron subsidence of Glen $\mathrm{Coe}$, and his early work on the petrology and classification of the Carboniferous volcanic rocks of the midland valley of Scotland, were stepping-stones to the immense task which he set himself in later years in the island of Mull. It is these investigations which have revolutionized our knowledge of the inner structure of British volcanoes; for to them we owe the recognition of ring dykes and ring complexes and the conception of igneous intrusion by ring fracture stoping.

Bailey's insatiable zest for scientific research has led him into other fields, and among notable con. tributions to Scottish geology must be reckoned the work he carried out with Kendall on the glaciation of East Lothian and the additions he made to the knowledge of the physical geography of Millstone Grit, Kimmeridgian and Cretaceous times. Farther afield his studies have dwelt on the tectonics of the Pennsylvania Piedmont and on the seismic origin of submarine canyons of the continental slope: and he has shown the importance to be ascribed to sub. marine landslips in the past record of the rocks, notably in the Palæozoic succession of Quebec.

Throughout a long and active career Bailey, by his enthusiasm, his powers of observation and his interpretative insight, has rendered splendid service to the science of geology, and his record of achievement is unsurpassed among living British geologists.

\section{Davy Medal}

The Davy Medal is awarded to Prof. I. M. Heilbron, professor of organic chemistry at the Imperial College of Science and Technology, in recognition of his many notable contributions to organic chemistry, especially to the chemistry of natural products of physiological importance.

After some early researches dealing with the chemistry of the coumarins, chromanes and benzopyrylium salts, Heilbron made his first really important contribution by his well-known investigation on the remarkable hydrocarbon, squalene, which occurs in certain fish oils. Almost simultaneously he established the structures of batyl and selachyl alcohols. His interest in fish oils being thus aroused, he next turned his attention to vitamin $\mathrm{A}$. $\mathrm{He}$ attacked this problem in the first instance by the use of the spectrograph with the collaboration of Morton, who was thereby led to develop methods for the quantitative estimation of this vitamin, which have since proved invaluable. Heilbron's contribution to the chemistry of vitamin A earned him an international reputation, and later led to the recognition of vitamin $\mathbf{A}_{2}$. He has attacked also the difficult problem of the synthesis of vitamin A and, although it has not yet reached its objective, his work in this direction has raised many points of great interest and importance.

Heilbron has also made notable contributions to our knowledge of the sterols and triterpenes. In this field, following pioneering work on the structure of ergosterol, he provided an elegant proof of the structure of vitamin $\mathrm{D}_{2}$ (calciferol) and has elucidated the structures of lumisterol, fucosterol and, more recently, zymosterol. In the triterpene field his most notable contribution has been his discovery of the key alcohol, basseol, which, in view of its facile conversion into $\beta$-amyrin, seems likely to play a significant part in the classification of triterpene chemistry.

The outbreak of war interrupted Heilbron's projected study of the lipochromes and sterols of the algal classes, a study likely to be of importance not only to the chemist but also to the botanist, for whom it may provide a new basis of classification. A résumé of this work formed the subject of a Hugo Müller lecture to the Chemical Society. British chemists are indebted to Heilbron more than to any other chemist for the introduction into Great Britain of the most refined new techniques. He has used 
extensively in his researches chromatographic absorption, microanalysis and high-vacuum distillation, while he was probably the first to recognize the potentialities of absorption spectra as a research tool. His influence has thus spread far beyond the circle of the many research chemists trained in his laboratories.

\section{Sylvester Medal}

The Sylvester Medal is awarded to Prof. J. E. Littlewood, Rouse-Ball professor of mathematics in the University of Cambridge, in recognition of his mathematical discoveries.

Among mathematicians, the name of Littlewood will always be associated with that of G. H. Hardy for the wonderful example of perfect teamwork in their fashioning of a new and rare instrument of mathematical precision during the second and third decades of the twentieth century. Into the theory of numbers, that subject where problems are so easy to state but so hard to prove, an entirely new spirit was infused when the methods of analysis were brought to bear upon it. The credit for attaining the highest results, for perfecting the methods, and for inspiring an enthusiastic following among so many of the ablest mathematicians at home and abroad, all belongs to Hardy and to Littlewood. Littlewood, who is by age the junior in this remarkable partnership, brought his own magnificent contribution, as Hardy himself has wholeheartedly testified. Littlewood, on Hardy's own estimate, is the finest mathematician he has ever known. He was the man most likely to storm and smash a really deep and formidable problem : there was no one else who could command such a combination of insight, technique, and power.

Littlewood's work covers a wide field of pure mathematics, extending from his fundamental discoveries in the realm of integral functions (1908) up to the present date. It was a happy event when Ramanujan, with his intuitive genius, proposed problems that brought out the fullest powers and skill of Littlewood and Hardy and their analytical theories. We can have no doubt that there is a peculiar fitness in the immediate succession of Littlewood to Hardy in this triennial award of the Sylvester Medal for mathematical research.

\section{Húghes Medal}

The Hughes Medal is awarded to Prof. M. L. E. Oliphant, Poynting professor of physics in the University of Birmingham, in recognition of his work in nuclear physics and mastery of modern methods of generating and applying high potentials.

Oliphant, initially under the general guidance of Rutherford, has made fundamental advances in the field of nuclear disintegration. With the aid of specially designed apparatus he has produced intense beams of protons and of the nuclei of heavy hydrogen, with homogeneous energy, the study of the reactions of which with light nuclei has proved very fruitful. The intensity of the beam which Oliphant has obtained has allowed effects to be produced at much lower voltages than had hitherto been available. The theoretically important disruption of the lithium nucleus has been investigated with particular care. In this connexion a separation of the two lithium isotopes was first effected, so that they could be separately studied, with a consequent greater certainty as to the reactions.

In Oliphant's researches the energy liberated in certain nuclear reactions has been measured to a remarkably high degree of accuracy, and the laws of conservation of mass-energy and of momentum have been verified. This is a matter of great importance for the understanding of nuclear reactions, and has also enabled the masses of the light atoms to be calculated very precisely.

As a result of work carried out by Oliphant with Harteck, on the bombardment of the nuclei of heavy hydrogen with like nuclei, two new light isotopes have been discovered, one of hydrogen and one of helium, both of mass number 3 . The nuclear reactions of beryllium and of boron have also been carefully investigated.

In the published accounts of the work Oliphant's name has often been associated with that of others, including Rutherford, but there is no doubt that he was responsible for the very specialized experimental technique, as well as for other contributions to the collaborative enterprise. Oliphant has been particularly successful in the design of apparatus. Besides that required for the researches to which reference has been made, he has been responsible for the development of the two-million-volt installation at Cambridge. During the War he has successfully carried out work of great importance. His fine record of achievement is fittingly recognized by the award of the Hughes Medal for "original discovery in the Physical Sciences, particularly electricity and magnetism or their applications".

\section{FORTHCOMING EVENTS}

\author{
(Meetings marked with an asterisk * are open to the public)
}

\section{Saturday, December 4}

GEOLOGISTS' Assocration (at the Geological Society, Burlington House, Piccadilly, London, W.1), at 2.30 p.m.-Dr. Alan Wood : "Basic English and its use in Geology" and "Organs of Reproduction in the Solenoporacee".

Shemfibld Metaldurgical Assoctatron (joint meeting with the SHEFIFLD SOCIETY OF ENGINEERS AND METALIURGISTS and the IRON AND STEEL INSTITUTE) (at the Royal Victoria Station Hotel, Oxygen Sub-Committee.

\section{Monday, December 6}

Royal Societr oF ARTS (at John Adam Street, Adelphi, London, W.C.2), at 1.45 p.m. -Mr. W. A. Robertson : "Timber-the Minor Products" (Cantor Lectures, 3).

SOCIETY OF CHEMICAL INDUSTRY (LONDON SECTION) (at the Chemical Society, Burlington House, Piccadilly, London, W.1), at 2.30 p.m.Prof. W. E. S. Turner, F.R.S. : "Glass for Use in the Chemical Inand Uses".

ROYAL GEOGRAPHICAL SOCIETY (at Kensington Gore, London, S.W.7), at 8 p.m. "Geography of Post-War Air Routes" (Discussion to be opened by Lieut.-Colonel Lord Brabazon; and Film, "Singapore to London").

\section{Tuesday, December 7}

ROYAT ANTHROPOLOGICAL INSTITUTH (at 21 Bedford Square, London, W.C.1), at 1.30 p.m.-Mr. L. Bohdanowicz: "The Polish Tartars".

Institution of CIVIL ENGINEERS (RAILWAY ENGINEERING DIVIsION) (at Great George Street, Westminster, London, S.W.1), at 5 p.m. -Mr. H. R. Reynolds : "Soil Mechanics and the Railway Engineer", Mr. M. F. Barbey: "Some Soil Mechanics Problems on the L.M.S. Railway":" ROYaL INSTrTution (at 21 Albemarle Street, London, W.1), at
5.15 p.m. - Prof. J. C. Drummond: "Food Problems of the PostW.15 p.m.-Prof. J. C. Drummond : "

\section{Wednesday, December 8}

ROYaL SocIETy of ARTS (at John Adam Street, Adelphi, London, W.C.2), at 1.45 p.m.-Mr. A. C. Bossom, M.P.: "Some Modern Methods of Construction Practised in America".

INSTITUTE OF FURL (at the Connaught Rooms, Great Queen Street, Kingsway, London, W.C.2), at 2.30 p.m.-Major-General K. C. Appleyard: "The Production and Use of Open-Cast Coal". 